\title{
Genetic comparison of water molds from embryos of amphibians Rana cascadae, Bufo boreas and Pseudacris regilla
}

\author{
Kori K. Ault, James E. Johnson, Holly C. Pinkart, R. Steven Wagner* \\ Department of Biological Sciences, Central Washington University, 400 E University Way, Ellensburg, Washington 98926, USA
}

\begin{abstract}
Water molds that cause the disease saprolegniasis have been implicated in widespread mortality of amphibian embryos. However, because of the limitations of traditional identification methods, water mold species involved in die-offs or utilized in ecological studies often remain unidentified or identified only as Saprolegnia ferax. Furthermore, water mold taxonomy requires revision, so very distinct organisms may all be called $S$. ferax. Recent DNA-based studies indicate that the diversity of water molds infecting amphibian embryos is significantly higher than what was previously known, but these studies rely on culture methods, which may be biased towards taxa that grow best under laboratory conditions. In this study, total embryo-associated DNA was extracted from 3 amphibian species in a pond in central Washington, USA. The internal transcribed spacer (ITS) region of DNA was amplified with primers capable of amplifying a broad array of eukaryotic microorgansisms, and was used to construct clone libraries. Individual clones were sequenced and relationships among newly recovered sequences and previously studied taxa were analyzed using phylogenetics. These methods recovered several new taxa in association with amphibian embryos. Samples grouped into 11 distinct phylotypes with ITS sequence differences ranging from 4 to $28 \%$. The water mold communities recovered differed among Rana cascadae, Bufo boreas, and Pseudacris regilla egg masses. Furthermore, the diversity of water molds increased as egg masses aged, and members comprising this diversity changed over time.
\end{abstract}

KEY WORDS: Saprolegnia - Water mold - Internal transcribed spacer - ITS · Cascades frog • Western toad $\cdot$ Pacific tree frog $\cdot$ Taxonomy $\cdot$ Disease ecology

\section{INTRODUCTION}

Infectious diseases can have devastating effects on population dynamics, and contribute to the current global biodiversity crisis (Daszak et al. 1999, Blaustein \& Kiesecker 2002). With extinction threatening at least one-third of all amphibian species (Stuart et al. 2004), it is essential to understand diseases that contribute to amphibian declines. Water molds of the phylum Oomycota are ubiquitous saprotrophs in freshwater systems, and are also known to cause the disease saprolegniasis in fish and amphibians (Scott 1964, Banks \& Beebee 1988, Blaustein et al. 1994,
Kiesecker et al. 2001b). Healthy adult amphibians do not commonly suffer from water mold infections, but embryos and larvae may be killed by saprolegniasis (Kiesecker \& Blaustein 1995, Romansic et al. 2006, Romansic et al. 2009). The extent and effects of water mold infections vary greatly between locations and seasons; in ponds stocked with fish that carry a virulent oomycete strain, up to $80 \%$ egg mortality has been reported in association with water mold infections. (Kiesecker \& Blaustein 1997).

Although water molds are recognized as important pathogens of amphibian embryos, these organisms are still poorly understood. Until recently, most am- 
phibian embryo infections were attributed to Saprolegnia ferax, and many water mold infection studies have not identified the pathogen beyond Saprolegnia sp. (Kiesecker \& Blaustein 1995, 1999, Kiesecker et al. 2001a,b, Romansic et al. 2006, Sagvik et al. 2008a,b). However, most identifications of either Saprolegnia sp. or $S$. ferax have been based on the general appearance of an infection rather than specific pathogen identification. More thorough studies of water mold infections use morphological identification (Blaustein et al. 1994), but this practice is inadequate because the morphology of these organisms does not reflect their phylogeny (Diéguez-Uribeondo et al. 2007, Johnson et al. 2008). Consequently, various studies of 'Saprolegnia' infections may actually be of diverse organisms.

Recent molecular work indicates that multiple water molds cause saprolegniasis, but the ecological consequences of this diversity have not been addressed. At least 7 phylotypes of water mold are associated with infected embryos (Johnson et al. 2008), and one study reports 12 different types (Petrisko et al. 2008). Of these, 3 species (Saprolegnia ferax, S. diclina, and Leptolegnia sp.) can cause mortality in controlled experiments (Kiesecker et al. 2001b, Fernandez-Beneitez et al. 2008, Ruthig 2009). Although these studies begin to explore the diversity of water molds, they rely on culture methods, which favor the isolation of taxa that grow best under culture conditions, not necessarily the taxa that are most prevalent or most important on the host. However, molecular methods can help to circumvent culture bias by constructing a clone library using all DNA from organisms associated with infected amphibian embryos. If multiple species co-occur on a single embryo, they may interact with one another (competitively or synergistically) to change the infection ecology. Competition among water molds on an embryo could lessen the overall harm to the amphibian, whereas synergistic interactions could increase mortality for those embryos exposed to multiple types of water mold. With the potential for such interactions, it is important to consider pathogen diversity when investigating water mold infections.

Diverse water molds may also respond differently to environmental factors. For example, stressors such as temperature, UV-B radiation, and $\mathrm{pH}$ can increase amphibian vulnerability to water molds (Banks \& Beebee 1988, Kiesecker \& Blaustein 1995, Hatch \& Blaustein 2000, Kiesecker et al. 2001a, Blaustein et al. 2003), but these responses may vary depending on the water molds present. Environmental stressors are generally evaluated for their effects on amphib- ians, but these stressors may also affect the water molds. Experimental studies show that some Saprolegnia infections are actually mitigated by nitrates in the water (Romansic et al. 2006), which indicates that nitrates affect water molds as well as amphibians. In the context of these complex interactions, water mold diversity should be considered in experimental studies of amphibian saprolegniasis.

Amphibians vary in their vulnerability to water mold infections. These differences may be due to the properties of the egg jelly or the ecology of egg laying behavior. For example, species such as Rana cascadae have a large, dense jelly envelope, which may be more difficult for hyphae to penetrate compared with the more delicate Bufo boreas jelly. Furthermore, the chemistry and composition of egg jelly may differ between species, which could confer varying resistance to saprolegniasis. Egg laying behavior may also play an important role in water mold infection because water molds spread throughout an egg mass primarily through direct hyphal contact. Eggs that are laid communally, or in larger egg masses, experience higher mortality because water mold infections can spread between embryos more easily (Kiesecker \& Blaustein 1997). Because different amphibian species have different jelly types and different laying behavior, there is a potential for different water molds to specialize in colonizing certain species.

Some circumstantial evidence indicates host specificity, or at least significant host preferences among water molds. Ruthig (2009) isolated a Saprolegnia species from Rana catesbeiana, but found a different genus of water mold, Leptolegnia, on Pseudacris crucifer embryos from the same pond. In addition, Robinson et al. (2003) found that water molds isolated from the same newt species in different ponds had similar DNA fingerprints, indicating that some pathogens may be species-specific. In several studies, multiple amphibian species were infected with a single strain of Saprolegnia (Kiesecker \& Blaustein 1995, 1999, Romansic et al. 2006, Touchon et al. 2006), but findings from such studies may not be ecologically relevant if different strains are specific to different hosts in natural systems. Furthermore, accurate identification of pathogens is important because strains of Saprolegnia differ in their virulence (Kiesecker et al. 2001b, Robinson et al. 2003). Given the morphological plasticity of these organisms, isolates identified as different 'strains' in these comparative virulence studies may actually be different species, or even different genera. Therefore, accurate identification is important. 
The present study uses a molecular approach to construct clone libraries to address the following hypotheses: (1) multiple types of water molds are found on the embryos of each amphibian species tested; (2) water mold communities differ among amphibian species, indicating some level of host specificity or preference; and (3) older egg masses host more diverse water mold communities, which would occur if older masses are exposed to more water molds. As a result, this study is designed to survey and compare the diversity of water mold associations with amphibians in a natural, aquatic system.

\section{MATERIALS AND METHODS}

Infected embryos were collected from Swamp Lake, WA $\left(52.40960^{\circ} \mathrm{N}, 62.8383^{\circ} \mathrm{E}\right)$, during the spring breeding seasons of 2008 and 2009. This is a shallow lake of approximately $121 \mathrm{ha}$; it is home to several amphibian species, but does not contain any fish. Three species of amphibian known to have water mold infections, the Cascades frog Rana cascadae, the western toad Bufo boreas, and the Pacific tree frog Pseudacris regilla, were chosen for this study. Swamp Lake is also the breeding site of the northwestern salamander Ambystoma gracile, but this species is less common and generally less affected by water molds, and was not included in this study. At this location, R. cascadae lay their eggs as soon as the pond begins to melt out in the spring, so the pond was monitored twice a week for breeding activity beginning mid-March to capture early stage infections.

For Rana cascadae, each egg mass encountered was sampled, assigned an identification number, and flagged for resampling. Embryos selected for collection were those visibly colonized with a water mold. For egg masses that were not visibly colonized, the embryos selected were those that appeared compromised in any way. Egg masses were resampled on 12, 15, and 19 May 2009, until all embryos either hatched or died.

Bufo boreas lay eggs communally in long strings of eggs that mix between breeding pairs to create large mats of embryos, so a modified sampling protocol was necessary. Colonized embryos were selected for collection from various locations around the mat, and each location was numbered and flagged. Subsequent samples were collected from the same flagged locations around the breeding area, again choosing embryos that were visibly colonized whenever possible. B. boreas embryos were resampled on 15, 19, and 23 May 2009, until all embryos either hatched or died.
The third amphibian species, Psuedacris regilla, lays eggs in small clutches of approximately 10-20 eggs, so when these embryos were encountered the entire egg mass was collected. With this strategy, resampling for $P$. regilla was not possible; all samples were collected on 29 May 2008.

Each embryo was thoroughly rinsed in $9 \mathrm{ml}$ sterile water, preserved in $1 \mathrm{ml} 70 \%$ ethanol in $1.5 \mathrm{ml}$ microcentrifuge tubes, and stored at $4{ }^{\circ} \mathrm{C}$. Examination of samples under a dissecting microscope to determine whether hyphae were penetrating into the egg jelly or simply present on the jelly surface was not practical in this study because of the advanced state of decomposition of some samples. Samples of Rana cascadae and Bufo boreas were grouped into early, middle, or late collection periods corresponding to the collection dates. Early, middle, and late designations generally correspond both to the overall development of the egg mass and the progression of infection. To standardize sample sizes between groups, we extracted DNA from 10 individual infected embryos from early, middle, or late collections of $R$. cascadae and B. boreas; all 10 samples of Pseudacris regilla were included.

To prepare for DNA extraction, each sample was centrifuged at $12846 \times \mathrm{g}$ for $2 \mathrm{~min}$, and ethanol decanted. Pellets were centrifuged again at $12846 \times$ $\mathrm{g}$ for $2 \mathrm{~min}$, and the remaining ethanol was removed by aspiration. DNA was extracted from the pellets using a DNeasy ${ }^{\circledR}$ Blood and Tissue Kit (QIAGEN), and stored at $-20^{\circ} \mathrm{C}$.

Amplification of the internal transcribed spacer (ITS) region of rDNA was achieved with the primers ITS1 and ITS4 (White et al. 1990). PCR reactions included $2 \mathrm{ml} 10 \times$ buffer (Teknova), $2.5 \mathrm{mM} \mathrm{MgCl}_{2}$, $200 \mu \mathrm{M}$ each dNTP, $0.4 \mu \mathrm{M}$ each primer, $1 \mathrm{U}$ Taq DNA polymerase, and $1 \mu \mathrm{l}$ DNA template in $20 \mu \mathrm{l}$ reactions. Amplifications were performed with 40 cycles of $94^{\circ} \mathrm{C}$ for $1 \mathrm{~min}, 54^{\circ} \mathrm{C}$ for $1 \mathrm{~min}, 72^{\circ} \mathrm{C}$ for $2 \mathrm{~min}$, and a final extension of $72^{\circ} \mathrm{C}$ for $7 \mathrm{~min}$.

For early, mid, and late collection groups, PCR products were pooled for each host and used to construct plasmid clone libraries. PCR fragments were ligated with $\mathrm{pGEM}^{\circledR}{ }^{\circledR} \mathrm{T}$ Easy Vector System (Promega) by incubation at room temperature for $1 \mathrm{~h}$, or at $4^{\circ} \mathrm{C}$ overnight, with $5 \mu \mathrm{l} 2 \mathrm{X}$ Rapid Ligation Buffer, $1 \mu \mathrm{l}$ pGEM ${ }^{\circledR}$-T Easy vector, $3 \mu \mathrm{l}$ PCR product, and $1 \mu \mathrm{l} 4$ DNA Ligase (3 Weiss units $\mu^{-1}$ ). Constructs were transformed into $50 \mu \mathrm{l}$ Escherichia coli JM109 chemically competent cells, which were mixed with $2 \mu$ of ligation reaction and incubated on ice for $20 \mathrm{~min}$ followed by a $45-60 \mathrm{~s}$ heat shock at $42^{\circ} \mathrm{C}$. SOC medium (950 $\mu$ l of $20 \mathrm{~g} \mathrm{l}^{-1}$ tryptone, $5 \mathrm{~g} \mathrm{l}^{-1}$ yeast 
extract, $0.5 \mathrm{~g} \mathrm{l}^{-1} \mathrm{NaCl}_{1} 0.95 \mathrm{~g} \mathrm{l}^{-1} \mathrm{MgCl}_{2}, 20 \mathrm{mM}$ glucose) was added, and samples were incubated at $37^{\circ} \mathrm{C}$ for $1.5 \mathrm{~h}$ with shaking. Transformed E. coli cells $(100 \mu \mathrm{l})$ were plated on Luria-Bertani agar $\left(10 \mathrm{~g} \mathrm{l}^{-1}\right.$ tryptone, $5 \mathrm{~g} \mathrm{l}^{-1}$ yeast extract, $10 \mathrm{~g} \mathrm{l}^{-1} \mathrm{NaCl}, 20 \mathrm{~g} \mathrm{l}^{-1}$ agar, $100 \mathrm{mg} \mathrm{l}^{-1}$ ampicillin, $\mathrm{pH}$ 7.0) with $20 \mu \mathrm{X}$-Gal and $100 \mu \mathrm{l}$ isopropyl- $\beta$-D-thiogalactoside and incubated overnight at $35^{\circ} \mathrm{C}$. All white colonies were screened for inserts by direct PCR amplification using the same conditions described previously. Amplification products were evaluated by electrophoresis on $1 \%$ agarose gel with $50 \mathrm{\mu g} \mathrm{ml}^{-1} 100 \mathrm{bp}$ ladder.

All successful amplifications were sequenced in the forward direction using the primer ITS1 by the University of Washington's High-Throughput Genomics Unit. Sequence assembly was performed using the program Staden 1.7.0 (Staden et al. 2000). For each distinct sequence, 2 representative samples were sequenced in the reverse direction using the primer ITS4. Some sequences were only found once, in which case that one sample was sequenced in the reverse direction. Each unique consensus sequence was matched to sequences in GenBank using BLASTN (Altschul et al. 1990) to assess the closest genus of eukaryotic microorganism. Samples that matched to the Oomycota (most closely matched to members of Saprolegnia, Leptolegnia, or Achyla) were used for further assessment of water mold diversity.

Sequence alignments were performed with ClustalX (Larkin et al. 2007) followed by visual alignment with Mesquite 2.72 (Maddison \& Maddison 2009). Phylogenetic analysis was performed using PAUP* $4.0 \mathrm{~b} 10$ (Sinauer Associates) with Aphanomyces frigidophilus (GenBank accession number FM999233) as an outgroup. Phylogenetic analysis included each unique water mold sequence plus all similar sequences in GenBank. The complete data set $(n=386)$ was used to construct a neighbor-joining tree (support values were determined by bootstrapping with 1000 replicates). Based on this tree, clades that contained sequences recovered from this study were identified and analyzed separately. Each clade was analyzed using maximum likelihood (bootstrap with 100 replicates) and neighbor-joining (bootstrap with 1000 replicates) algorithms. From these analyses, sequences were chosen that represented the topology of each clade for inclusion in construction of summary trees $(n=49)$ using maximum likelihood (bootstrap with 100 replicates) and neighbor-joining (bootstrap with 1000 replicates) programs.

To assess genetic distances between samples within a clade, Kimura 2-parameter (K2P) distance matrices were calculated. A distance matrix was also calculated for all of the samples from this study. Samples were considered to belong to unique phylotypes if they differed by more than 3\% (O'Brien et al. 2005).

\section{RESULTS}

Multiple phylotypes of water molds were associated with amphibian embryos, and communities of water molds differed among amphibian species and collection times. In addition to water molds, a number of algae and other eukaryotic microorganisms were associated with amphibian egg masses. These microeukaryote communities differed among amphibian species and collection times.

From 130 samples sequenced for this study, 117 high quality sequences were recovered. Sequences were considered 'high quality' if they had clear base calls and were at least $450 \mathrm{bp}$ long. Of these, 60 sequences were from water molds, 45 were from algae, and 12 were from other eukaryotic microorganisms (Table 1). Recovered water mold sequences ranged

Table 1. Occurrence of microorganism groups in Bufo boreas, Rana cascadae and Pseudacris regilla. Number of microorganism internal transcribed spacer sequences recovered from each egg mass grouping as identified by the closest BLAST match. All usable sequence data are included $(n=117)$. No microorganism sequences were recovered from early $R$. cascadae egg masses

\begin{tabular}{|c|c|c|c|c|c|c|}
\hline & \multicolumn{3}{|c|}{ B. boreas } & \multicolumn{2}{|c|}{ R. cascadae } & \multirow[t]{2}{*}{$P$. regilla } \\
\hline & Early & Mid & Late & Mid & Late & \\
\hline \multicolumn{7}{|l|}{ Algae } \\
\hline Chlamydomonas & - & - & - & 2 & - & - \\
\hline Dunaliella sp. 1 & - & 2 & - & 9 & 16 & - \\
\hline Dunaliella sp. 2 & - & 2 & 7 & 4 & - & - \\
\hline Synura & - & - & - & 1 & - & - \\
\hline Urospora & - & - & - & 2 & - & - \\
\hline \multicolumn{7}{|l|}{ Water molds } \\
\hline Achlya & - & 1 & 3 & - & - & - \\
\hline Saprolegnia & 2 & 26 & 25 & 1 & 2 & - \\
\hline \multicolumn{7}{|l|}{ Other } \\
\hline Alveolate & - & 2 & - & - & - & - \\
\hline Chilodonella (ciliate) & - & 1 & - & - & - & - \\
\hline Pholiota (fungus) & - & - & - & - & - & 1 \\
\hline Spumella-like (flagellate) & - & - & 2 & - & - & - \\
\hline Stylonychia (ciliate) & - & - & 3 & - & - & - \\
\hline Tetrahymena (ciliate) & 2 & 1 & - & - & - & - \\
\hline
\end{tabular}


Table 2. Identification of sequenced samples. Sample labels of MR, LR, EB, MB, or LB identify the water mold source as mid Rana cascadae, late $R$. cascadae, early Bufo boreas, mid B. boreas, or late B. boreas egg masses, respectively

\begin{tabular}{|lccccc}
\hline Sample ID & No. sequences recovered & Clade & Phylotype & Identification & GenBank accession no. \\
\hline MR87 & 1 & A & A1 & Saprolegnai ferax & JQ974983 \\
EB13f & 1 & A & A1 & Saprolegnia ferax & JQ974984 \\
LR11 & 1 & B & B1 & Saprolegnia sp. & JQ974985 \\
LB52 & 7 & B & B1 & Saprolegnia sp. & JQ974986 \\
MB35/MB13 & 12 & B & B1 & Saprolegnia sp. & JQ974987 \\
LB26 & 1 & B & B2 & Saprolegnia sp. & JQ974988 \\
EB11 & 1 & C1 & Saprolegnia torulosa & JQ974989 \\
MB70 & 1 & D1 & Saprolegnia sp. & JQ974990 \\
LR2 & 1 & E & E1 & Saprolegnia sp. & JQ974991 \\
MB12 & 11 & E & E1 & Saprolegnia sp. & JQ974992 \\
LB 46 & 17 & E & F1 & Saprolegnia sp. & JQ974993 \\
MB60/MB24 & 2 & G1 & G1 & Achlya treleaseana & JQ974994 \\
LB20 & 1 & G2 & Achlya oligacantha & JQ974995 \\
MB88 & 1 & G & G3 & Achlya sp. & JQ974997 \\
LB35 & 1 & G & G4 & Achlya sp. & JQ974998 \\
LB63 & 1 & & & \\
\hline
\end{tabular}

from 621 to $881 \mathrm{bp}$ long, algae sequences were 467 to $885 \mathrm{bp}$, and the other eukaryotic microorganisms were 479 (Pholiota) to 716 (Spumella-like flagellate) bp long. Identification of water mold sequences and GenBank accession numbers are presented in Table 2.

The assortment of eukaryotic microorganisms associated with amphibian embryos differed among Bufo boreas, Rana cascadae, and Pseudacris regilla egg masses. $B$. boreas egg masses hosted the greatest numbers of water molds, but also had associated algae and other microorganisms (Table 1). In contrast, algae were primarily associated with $R$. cascadae egg masses, which had few associated water molds and no other eukaryotic microorganisms. Of the algae present on $R$. cascadae embryos, 5 genera were found on mid $R$. cascadae egg masses, but only the genus Dunaliella was present on late $R$. cascadae egg masses. Interestingly, early $R$. cascadae had no evidence of eukaryotic microorganisms. Only one phylotype was recovered from the $P$. regilla egg masses, and it was the only true fungus (Pholiota) detected in this study.

Water molds recovered in this study grouped into 7 distinct clades, designated A-G (Fig. 1). Clades A-F included a number of isolates from GenBank that have been identified as species of Saprolegnia, whereas clade $\mathrm{G}$ included a number of isolates that have been identified as species of Achlya. The number of members and genetic diversity of each clade are shown in Table 3. Genetic distances between samples from different clades ranged from 9.8 to $28.2 \%$ (Table 4 ). The 7 clades included 11 distinct phylotypes, separated from each other by at least a
$3 \%$ K2P genetic difference (Table 4); within-phylotype sequences differed by less than $0.7 \%$.

Clade A consisted of a group of highly similar sequences, and included samples from early Bufo boreas and mid Rana cascadae embryos. The 2 samples recovered had a K2P genetic distance of $0.2 \%$ (Table 4), and were therefore considered to belong to a single phylotype, A1. Other members of this clade have been morphologically identified as Saprolegnia ferax in GenBank, including a sample (EU124763) that is identical to A1 and was previously identified morphologically as $S$. ferax (Johnson et al. 2008).

Clade B included samples from collection groups mid and late Bufo boreas and late Rana cascadae.

Table 3. Sequence diversity and support for each clade, showing the number of sequences (n) from GenBank that fall into each clade, the bootstrap support for each clade, and the range of Kimura 2-parameter percent distances within each clade. Bootstrap values are reported from a neighbor-joining (NJ) tree with 1000 replicates and a maximum likelihood (ML) consensus tree with 100 replicates

\begin{tabular}{|c|c|c|c|c|}
\hline \multirow[t]{2}{*}{ Clade } & \multirow[t]{2}{*}{$\mathrm{n}$} & \multicolumn{2}{|c|}{ Bootstrap (\%) } & \multirow[t]{2}{*}{ Distance (\%) } \\
\hline & & NJ & $\mathrm{ML}$ & \\
\hline A & 70 & 100.0 & 88 & $0-7.7$ \\
\hline B & 33 & 100.0 & 97 & $0-7.0$ \\
\hline $\mathrm{C}$ & 11 & 100.0 & 90 & $0-4.9$ \\
\hline $\mathrm{D}$ & 4 & 100.0 & 10 & $0.1-7.7$ \\
\hline $\mathrm{E}$ & 37 & 96.4 & 99 & $0-19$ \\
\hline $\mathrm{F}$ & 13 & 99.3 & 87 & $0-6.4$ \\
\hline $\mathrm{G}$ & 9 & 75.8 & 75 & $3.6-18.1$ \\
\hline
\end{tabular}




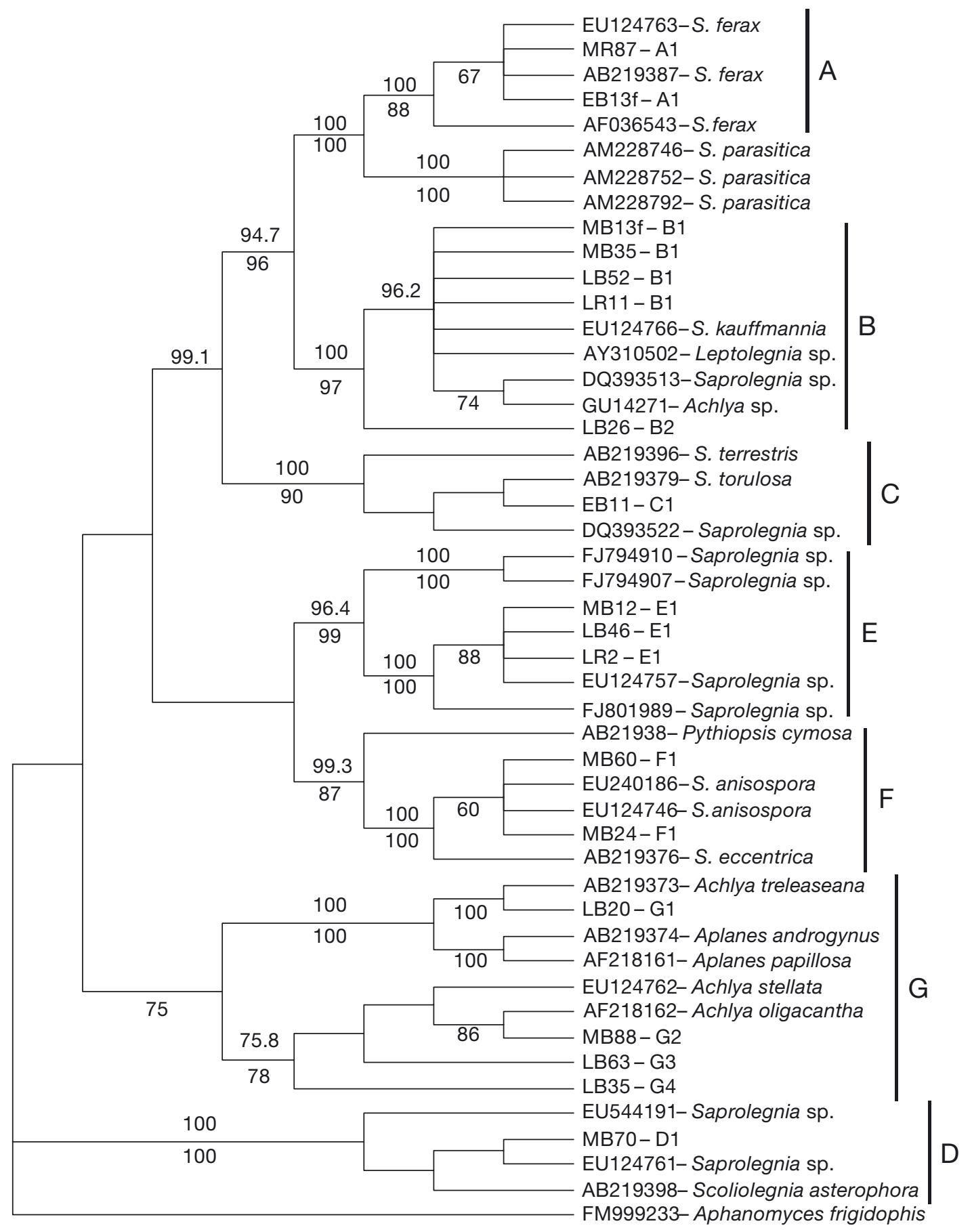

Fig. 1. Maximum likelihood summary tree. Representative water mold taxa (all S.: Saprolegnia) were chosen from a larger neighbor-joining tree $(n=386)$ to represent the diversity of sequences in each clade. Bootstrap values $>60$ are shown from a neighbor-joining tree with 1000 replicates (above) and a maximum likelihood tree with 100 replicates (below)

Other members of this clade have been identified as Achlya, Leptolegnia, or Saprolegnia species in GenBank. However, our laboratory has previously used morphology to identify members of this clade (EU124766) as Saprolegnia sp. (Johnson et al. 2008).
Following initial analyses of all taxa $(\mathrm{n}=386)$ using neighbor-joining, clade B was analyzed separately with neighbor-joining and maximum likelihood. The samples recovered divided into 2 distinct phylotypes, B1 and B2 (Fig. 1). In addition to belonging to sepa- 
Table 4. Distance matrix. Range of Kimura 2-parameter percent distances among water mold phylotypes from this study. Distances within a phylotype are in bold. NA indicates the comparison of a phylotype with a single sample to itself

\begin{tabular}{|c|c|c|c|c|c|c|c|c|c|c|c|}
\hline & A1 & B1 & B2 & $\mathrm{C} 1$ & D1 & E1 & F1 & G1 & G2 & G3 & G4 \\
\hline A1 & 0.2 & & & & & & & & & & \\
\hline B1 & $9.5-10.3$ & $0.0-0.2$ & & & & & & & & & \\
\hline B2 & $12.3-12.4$ & $4.4-5.7$ & NA & & & & & & & & \\
\hline $\mathrm{C} 1$ & $11.6-12.2$ & $12.9-13.6$ & 16.7 & NA & & & & & & & \\
\hline D1 & $24.6-25.4$ & $26.8-27.9$ & 26.0 & 25.4 & NA & & & & & & \\
\hline E1 & $23.4-24.4$ & $23.3-25.0$ & $16.9-17.0$ & 22.5 & $20.6-21.5$ & 0.0 & & & & & \\
\hline $\mathrm{F} 1$ & $19.6-20.1$ & $20.9-22.1$ & $22.0-22.1$ & $16.7-16.9$ & $14.7-15.2$ & $18.5-18.9$ & 0.7 & & & & \\
\hline G1 & $21.7-22.4$ & $22.7-23.8$ & 23.9 & 22.1 & 22.1 & $25.3-26.0$ & $17.3-17.6$ & NA & & & \\
\hline G2 & $24.8-25.0$ & $22.9-24.0$ & 23.9 & 22.4 & 18.3 & $22.5-23.3$ & $15.3-15.5$ & 15.4 & NA & & \\
\hline G3 & $26.3-26.7$ & $24.4-24.6$ & 19.3 & 23.5 & 19.8 & $17.3-17.5$ & $16.8-17.0$ & 17.9 & 3.6 & NA & \\
\hline G4 & $22.3-23.1$ & $14.8-17.1$ & 22.1 & 20.8 & 21.3 & $22.8-23.2$ & $16.8-16.9$ & 18.0 & 7.0 & 6.5 & NA \\
\hline
\end{tabular}

rate sub-clades within Clade B, members of B1 differed from B2 by pairwise distances of greater than $4 \%$, whereas distances within phylotype B1 are $0-$ $0.2 \%$ (Table 4 ).

Several clades only contained one phylotype from this study. Clade $\mathrm{C}$ included a single sample from early Bufo boreas embryos, designated phylotype C1. This sequence was most similar to AB219379, identified as Saprolegnia torulosa, with a genetic distance of $<0.6 \%$. Clade D included a single sequence from mid $B$. boreas embryos, phylotype D1, which was $<0.1 \%$ different from a sample (EU124761) previously identified morphologically as a species of Saprolegnia (Johnson et al. 2008). Clade E included genetically identical samples isolated from mid and late $B$. boreas and late Rana cascadae collections (Table 4). These sequences, identified as phylotype E1, are identical to EU124757, which is from a culture identified morphologically as a species of Saprolegnia (Johnson et al. 2008). Clade F included 2 sequences from mid $B$. boreas egg masses; these differed by $0.7 \%$ and therefore belong to a single phylotype, F1. The majority of sequences in this clade have been identified in GenBank as $S$. anisospora, including EU24186, which is identical to members of F1.

Clade $\mathrm{G}$ included sequences from mid and late Bufo boreas egg masses. Unlike Clades A-F, all members of this clade were identified in GenBank as Achlya. Within this clade, each individual sample yielded a different phylotype (designated G1-4) with genetic distances ranging from 3.6 to $18 \%$ (Table 4 ).

Water molds varied between Rana cascadae and Bufo boreas egg masses, and differed with collection time (Fig. 2). Overall, only 3 of the 11 phylotypes were present on both $R$. cascadae and B. boreas egg masses. These 3 phylotypes were Saprolegnia ferax (A1) and the 2 most prevalent types of water mold, B1 and E1. Eight phylotypes were unique to $B$. boreas egg masses, but no phylotypes were unique to $R$. cascadae egg masses; all 3 phylotypes found on $R$. cascadae were also found on $B$. boreas.

The diversity of water molds infecting an amphibian species increased with time (Fig. 3). However, the phylotypes present changed over time. Only one water mold sample was recovered from mid Rana cascadae embryos, and it differed from the phylotypes on late $R$. cascadae samples (Fig. 2). Similarly, phylotypes that we found on early, mid, and late Bufo boreas embryos all differed from each other except for the most prevalent phylotypes, B1 and E1 (Fig. 2).

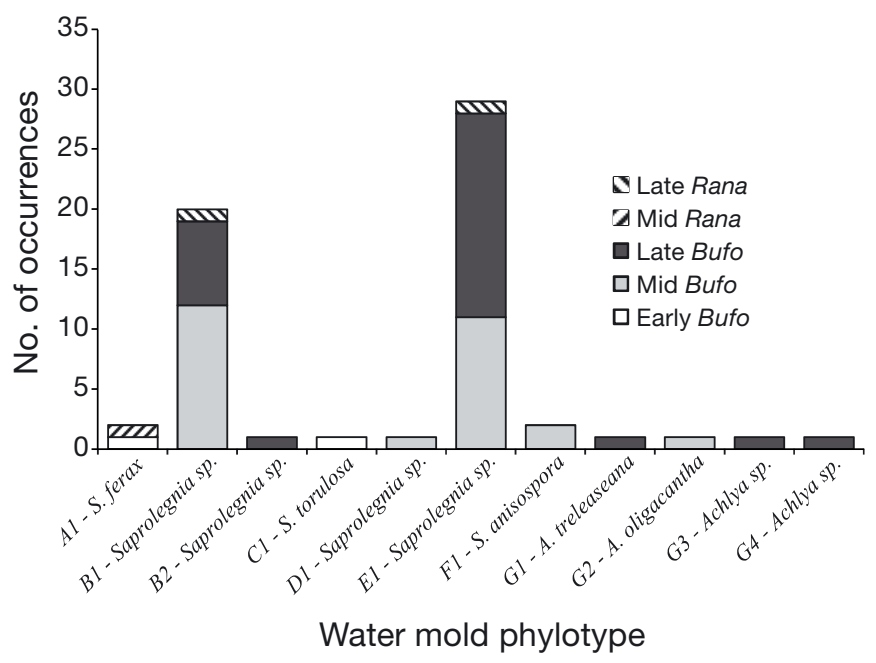

Fig. 2. Frequency of water mold phylotypes recovered, showing the number of samples recovered from each collection group (early, mid, or late Rana cascadae or Bufo boreas) for each distinct phylotype. See Fig. 1 for full species names 


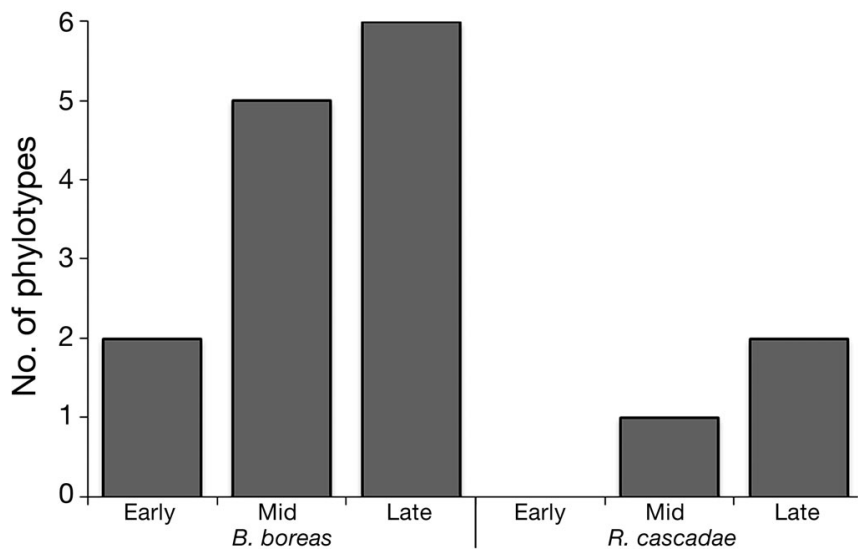

Fig. 3. Frequency of water mold phylotypes recovered from Bufo boreas and Rana cascadae with respect to collection time (early, mid, or late)

\section{DISCUSSION}

All 3 hypotheses proposed in this study were supported: (1) multiple types of water molds were found on each amphibian embryo species, (2) water mold communities differed among amphibian species, and (3) older egg masses hosted more diverse communities of water mold. In addition to finding diverse water molds, other eukaryotic organisms were recovered.

\section{Water mold diversity}

Multiple types of water molds were found on each amphibian species, confirming the first hypothesis. Eleven distinct phylotypes were associated with Bufo boreas embryos, and 3 of those were also found on Rana cascadae embryos (Fig. 2). However, 7 of the phylotypes each came from a single sample, and another 2 phylotypes were each found from only 2 samples. With such low repeated recovery of phylotypes, we believe that additional water mold phylotypes could be found with increased sampling effort.

The water molds recovered in this study differed from those previously reported in association with amphibians. The majority of studies have reported that $S$. ferax is the water mold responsible for amphibian saprolegniasis (Kiesecker \& Blaustein 1995, 1997, Kiesecker et al. 2001a,b). The phylotype most similar to isolates commonly identified as Saprolegnia ferax (A1) was found on both Rana cascadae and Bufo boreas egg masses, but only one representative sequence was detected from each amphibian species. Although the idea that $S$. ferax is important to amphibian saprolegniasis is not contradicted by these results, $S$. ferax was not among the most prevalent water molds isolated from infected amphibian embryos. Other authors have reported $S$. diclina and Leptolegnia sp. infecting amphibian embryos (Fernandez-Beneitez et al. 2008, Ruthig 2009), but these species were not found here. In contrast with previous research, the most prevalent types of water mold recovered, phylotypes B1 and E1, were most closely related to unidentified Saprolegnia species.

Phylotype B1 belongs to Clade B, which includes samples identified in GenBank as Saprolegnia, Leptolegnia, and Achlya. However, this apparent taxonomic diversity is probably the result of misidentification or bad taxonomy rather than true diversity, because clade members differ from each other by less than $2 \%$ and the clade is strongly supported (Fig. 1). A member of Clade B (EU124766) has been identified morphologically as $S$. kauffmanniana (Johnson et al. 2008), so phylotypes B1 and B2 were also considered to be species of Saprolegnia. Because B1 was present on both Rana cascadae and Bufo boreas egg masses and was the second most prevalent phylotype recovered in this study $(\mathrm{n}=20)$, it warrants further taxonomic description and consideration as an important amphibian Saprolegnia species.

The most prevalent phylotype, E1, is also an unidentified species of Saprolegnia. E1 was found on both Rana cascadae and Bufo boreas egg masses, and was the most commonly recovered water mold on amphibian eggs $(n=28)$. Clade E primarily includes sequences that have not been assigned species names in GenBank, but E1 is clearly a significant amphibian embryo associate. Infection studies, however, will be necessary to determine whether this organism is an amphibian pathogen.

In addition to the 3 species found on both Rana cascadae and Bufo boreas egg masses, 4 other Saprolegnia species were unique to $B$. boreas samples. They include Saprolegnia anisospora (F1), S. torulosa (C1) and 2 other Saprolegnia phylotypes (B2 and D1). As with the other taxa reported here (besides $S$. ferax), $S$. anisospora and $S$. torulosa are not known amphibian pathogens, but their association with these embryos warrants infection experiments to determine whether they are pathogens or opportunists.

Four of the phylotypes recovered (G1-4) belong to Clade $\mathrm{G}$, which consists primarily of samples identified as Achlya sp. in GenBank. Similarly to Saprolegnia, Achlya is not a monophyletic group and requires taxonomic revision. We excluded a number of species, including Achlya prolifera (the type of Achlya), because they are quite genetically distinct from all 
other species recovered in this analysis. In contrast, the phylogenetic analyses included a number of species from the subgenus Centroachlya. The morphology-based taxonomy from Johnson (1956) of the Saprolegniaceae is out of date and not supported by phylogenies based on molecular information. Plasticity of morphological characters and differences in interpretation have resulted in inconsistent identifications; consequently, names for taxa associated with sequences in GenBank are often suspect. Although Clade $\mathrm{G}$ does not include the type species for Achlya, we considered Clade $\mathrm{G}$ to be Achlya because all members within the clade are identified as Achlya. Achlya has not previously been reported from amphibian embryos, and the phylotypes discovered here may represent a new group of amphibian embryo pathogens.

\section{Species-specific differences in water mold communities}

The water mold communities associated with an egg mass differed between amphibian species, indicating some level of host specificity or preference. Interestingly, the only phylotype found on both Rana cascadae and Bufo boreas that could be assigned a species designation was Saprolegnia ferax. The ubiquity of this species may partially explain why it has historically been credited with all amphibian embryo infections, even though it was not the most commonly detected water mold in this study. The most prevalent water molds, B1 and E1, were the only other 2 phylotypes found on both $R$. cascadae and $B$. boreas. Although pathogenicity still needs to be established for B1 and E1, their prevelance and ubiquity supports the idea that B1 and E1 may be more important amphibian embryo pathogens than those previously described in the literature. Considering the molecular approach of this study, which did not rely on culture methods, it is possible that the ubiquitous B1 and E1 do not grow as well in culture as $S$. ferax, S. diclina, or Leptolegnia sp., and as such have been overlooked in terms of their importance to amphibian infections.

Four phylotypes of Saprolegnia were unique to Bufo boreas embryos: S. anisospora (F1), S. torulosa (C1), B2, and D1. However, no phylotypes were unique to Rana cascadae egg masses. This may indicate that $S$. anisospora (F1), S. torulosa (C1), B2, and D1 are host specific to $B$. boreas embryos, and no species are specific to $R$. cascadae embryos. Alternatively, it may indicate that $R$. cascadae are more resistant to water mold infections and only the strongest pathogens are able to infect them. As B1 and E1 were the most prevalent water molds, and exhibited high virulence in amphibians (S. Brady pers. comm.), Central Washington University, they would be likely to infect the more resistant $R$. cascadae embryos.

\section{Egg mass age and water mold community diversity}

The diversity and species of water molds represented by phylotypes increased over time in both Bufo boreas and Rana cascadae egg masses (Fig. 3). The members comprising this diversity also changed over time. It does not seem that the number of different water molds infecting an egg mass increases with time because they have longer exposure to environmental water molds. Rather, the water mold communities appear to be successional. Only the most prevalent phylotypes, B1 and E1, persisted between collection times (Fig. 3). Succession of water molds may indicate competition among phylotypes. Early colonizers may be better at initially infecting an egg mass, but once the egg mass is compromised the colonizers are outcompeted by more opportunistic water molds. Some water molds associated with amphibian embryos are probably saprotrophs, and can only infect an egg mass after embryos have been killed by a different type of water mold. Saprolegnia ferax plays a unique role in the timeline of colonization-it was the first species to colonize $R$. cascadae egg masses, and was one of the 2 phylotypes found in early $B$. boreas egg masses. Although many water molds infect egg masses, $S$. ferax may be one of the important initial colonizers.

\section{Other eukaryotic microorganisms}

Although water molds were the most common taxa recovered $(n=60)$, many algae $(n=45)$ were found as well (Table 1). Algae can have a symbiotic relationship with some amphibian species (Gilbert 1944). The gelatinous properties of an amphibian egg mass can limit oxygen transmission to embryos, but photosynthetic algae can produce oxygen within the mass. We found algae in both Bufo boreas and Rana cascadae samples, but $R$. cascadae egg masses had more algal associations. This is not surprising considering that other species of Rana, such as R. sylvatica, are among the species known to host symbiotic algae (Pinder \& Friet 1994). R. cascadae embryos may be 
more reliant on algae for oxygen production than $B$. boreas embryos because of the properties of their egg masses. $R$. cascadae have more dense, round egg masses that could limit oxygen diffusion under low oxygen conditions, whereas $B$. boreas lay their eggs in long strings that allow for greater exposure of embryos to the environment. Interestingly, mid $R$. cascadae egg masses hosted 5 algal genera, but only the genus Dunaliella was detected in late $R$. cascadae egg masses. This may indicate that multiple algal species initially infect an egg mass, but Dunaliella is is the only genus that is able to persist and become the dominant symbiont.

In addition to algae, other non-water-mold eukaryotic microorganisms were recovered. The only sequence recovered from Pseudacris regilla egg masses was a species of Pholiota. Because Pholiota is a genus of wood-rotting, mushroom-forming fungi, most likely a spore was simply present on an egg mass, but not infecting it. Several protists were found in association with Bufo boreas egg masses. These protists may have been associated with the egg masses because of the nutrient-rich environment created by the diverse community of water molds and algae infecting the embryos. The diverse assortment of microorganisms associated with amphibian embryos illustrates the role of egg masses in contributing to the diversity and complexity of a pond ecosystem.

\section{CONCLUSIONS}

It is clear from this study that types of water mold other than just Saprolegnia ferax, S. diclina, and Leptolegnia sp. are involved in colonization of amphibian embryos. At least 11 phylotypes of water mold were associated with amphibian embryos, but more sampling is needed to definitively characterize the complete diversity of water molds involved in colonization of amphibian embryos. Furthermore, infection experiments are needed in order to fulfill Koch's postulates and determine which phylotypes are primary pathogenic colonizers, which are opportunistic pathogens, and which are simply saprotrophs. Infection experiments are also needed to compare the relative virulence of different water molds, and investigate interactions between phylotypes. Finally, the host associations reported here should be explored to confirm specificity.

Although infection experiments are still needed to confirm which phylotypes are pathogenic, the prevalence of B1 and E1 may implicate them as important amphibian embryo pathogens. Researchers should not assume that all amphibian saprolegniaisis can be attributed to Saprolegnia ferax. According to the findings of this study, it is more likely that B1 or E1 is present, especially for Bufo boreas. Furthermore, some water mold infections may be due to Achlya, not Saprolegnia.

When investigating the ecology of water mold infections, it is important to recognize that different amphibian species host different communities of water molds. Because significant host associations may exist, infecting eggs of one species with water molds isolated from a different amphibian species may not be ecologically relevant.

Competition among phylotypes could be important to the infection ecology of an egg mass, so those attempting to infect amphibian embryos should consider the complexity of environmental infections when designing infection experiments. We have performed preliminary experiments that show that the mortality of embryos exposed to multiple water molds differs from the mortality of those exposed to a single water mold. It is clear that water molds associated with amphibian embryos represent diverse and dynamic communities, and the complexity of these systems should be considered as part of our understanding of amphibian embryo ecology.

\section{LITERATURE CITED}

Altschul SF, Gish W, Miller W, Myers EW, Lipman DJ (1990) Basic local alignment search tool. J Mol Biol 215:403-410

> Banks B, Beebee TJC (1988) Reproductive success of natterjack toads Bufo calamita in two contrasting habitats. J Anim Ecol 57:475-492

> Blaustein AR, Kiesecker JM (2002) Complexity in conservation: lessons from the global decline of amphibian populations. Ecol Lett 5:597-608

Blaustein AR, Hokit DG, O'Hara RK, Holt RA (1994) Pathogenic fungus contributes to amphibian losses in the Pacific Northwest. Biol Conserv 67:251-254

Blaustein AR, Romansic JM, Kiesecker JM, Hatch AC (2003) Ultraviolet radiation, toxic chemicals and amphibian population declines. Divers Distrib 9:123-140

Daszak P, Berger L, Cunningham AA, Hyatt AD, Green DE, Speare R (1999) Emerging infectious diseases and amphibian population declines. Emerg Infect Dis 5: 735-748

> Diéguez-Uribeondo J, Fregeneda-Grandes JM, Cerenius L, Pérez-Iniesta E and others (2007) Re-evaluation of the enigmatic species complex Saprolegnia diclina-Saprolegnia parasitica based on morphological, physiological and molecular data. Fungal Genet Biol 44:585-601

> Fernández-Benéitez MJ, Ortiz-Santaliestra ME, Lizana M, Diéguez-Uribeondo J (2008) Saprolegnia diclina: another species responsible for the emergent disease 'Saprolegnia infections' in amphibians. FEMS Microbiol Lett 279:23-29 
Gilbert PW (1944) The alga-egg relationship in Ambysoma maculatum, a case of symbiosis. Ecology 25:366-369

Hatch AC, Blaustein AR (2000) Combined effects of UV-B, nitrate, and low $\mathrm{pH}$ reduce the survival and activity level of larval cascades frogs (Rana cascadae). Arch Environ Contam Toxicol 39:494-499

Johnson TW Jr (1956) The genus Achlya: morphology and taxonomy. University of Michigan Press, Ann Arbor, MI

Johnson JE, Belmont SF, Wagner RS (2008) DNA barcoding as a means to identify organisms associated with amphibian eggs. Herpetol Conserv Biol 3:116-127

Kiesecker JM, Blaustein AR (1995) Synergism between UV-B radiation and a pathogen magnifies amphibian embryo mortality in nature. Proc Natl Acad Sci USA 92: 11049-11052

Kiesecker JM, Blaustein AR (1997) Influences of egg laying behavior on pathogenic infection of amphibian eggs. Conserv Biol 11:214-220

Kiesecker JM, Blaustein AR (1999) Pathogen reverses competition between larval amphibians. Ecology 80: 2442-2448

Kiesecker JM, Blaustein AR, Belden LK (2001a) Complex causes of amphibian population declines. Nature 410: 681-684

Kiesecker JM, Blaustein AR, Miller CL (2001b) Transfer of a pathogen from fish to amphibians. Conserv Biol 15: 1064-1070

Larkin MA, Blackshields G, Brown NP, Chenna R and others (2007) Clustal W and Clustal X version 2.0. Bioinformatics 23:2947-2948

Maddison WP, Maddison DR (2009) Mesquite: a modular system for evolutionary analysis. Available at http:// mesquiteproject.org

O'Brien HE, Parrent JL, Jackson JA, Moncalvo JM, Vilgalys R (2005) Fungal community analysis by large-scale sequencing of environmental samples. Appl Environ Microbiol 71:5544-5550

Petrisko JE, Pearl CA, Pilliod DS, Sheridan PP, Williams CF, Peterson CR, Bury RB (2008) Saprolegniaceae identified on amphibian eggs throughout the Pacific Northwest, USA, by internal transcribed spacer sequences and phylogenetic analysis. Mycologia 100:171-180

Editorial responsibility: Cynthia Carey,

Boulder, Colorado, USA
Pinder A, Friet S (1994) Oxygen transport in egg masses of the amphibians Rana sylvatica and Ambystoma maculatum: convection, diffusion and oxygen production by algae. J Exp Biol 197:17-30

Robinson J, Griffiths RA, Jeffries P (2003) Susceptibility of frog (Rana temporaria) and toad (Bufo bufo) eggs to invasion by Saprolegnia. Amphib-Reptil 24:261-268

Romansic JM, Diez KA, Higashi EM, Blaustein AR (2006) Effects of nitrate and the pathogenic water mold Saprolegnia on survival of amphibian larvae. Dis Aquat Org 68:235-243

Romansic JM, Diez KA, Higashi EM, Johnson JE, Blaustein AR (2009) Effects of the pathogenic water mold Saprolegnia ferax on survival of amphibian larvae. Dis Aquat Org 83:187-193

Ruthig GR (2009) Water molds of the genera Saprolegnia and Leptolegnia are pathogenic to the North American frogs Rana catesbeiana and Pseudacris crucifer, respectively. Dis Aquat Org 84:173-178

Sagvik J, Uller T, Olsson M (2008a) A genetic component of resistance to fungal infection in frog embryos. Proc Biol Sci 275:1393-1396

- Sagvik J, Uller T, Stenlund T, Olsson M (2008b) Intraspecific variation in resistance of frog eggs to fungal infection. Evol Ecol 22:193-201

Scott WW (1964) Fungi associated with fish diseases. Dev Indust Microbiol 5:109-123

Staden R, Beal KF, Bonfield JK (2000) The STADEN package, 1998. Methods Mol Biol 132:115-130

- Stuart SN, Chanson JS, Cox NA, Young BE, Rodrigues ASL, Fischman DL, Waller RW (2004) Status and trends of amphibian declines and extinctions worldwide. Science 306:1783-1786

Touchon JC, Gomez-Mestre I, Warkentin KM (2006) Hatching plasticity in two temperate anurans: responses to a pathogen and predation cues. Can J Zool 84:556-563

White TJ, Bruns T, Lee S, Taylor J (1990) Amplification and direct sequencing of fungal ribosomal RNA genes for phylogenetics. In: Innis MA, Gelfand DH, Sninsky JJ, White TJ (eds) PCR Protocols: a guide to methods and applications. Academic Press, New York, NY, p 315-322

Submitted: May 25, 2010; Accepted: February 9, 2012

Proofs received from author(s): June 8, 2012 